\section{THE ROLE OF CHEMISTRY IN COMBATING TROPICAL DISEASES*}

\author{
By SIR IAN HEILBRON, F.R.S.
}

$\mathrm{T}^{\circ}$ O a great Colonial Power such as Britain, the control of the insect-borne diseases, malaria and trypanosomiasis, the vectors of which are respectively the Anopheles mosquito and the tsetse fly, is of paramount importance. Malaria, which claims anything from 300 to 800 million victims a year, with an annual death roll of 3 to 4 million, is the most prevalent of all human infectious diseases and the worst scourge with which we have to contend throughout all our tropical and sub-tropical Colonies. It is not only responsible directly for enormous damage to health but it so lowers vitality by its destruction of blood cells that other infections are enabled to create perhaps even greater destruction than the malaria itself.

The direct cause of all this sickness is a protozoon belonging to the genus Plasmodium. Of the three species, $P$. vivax, $P$. falciparum and $P$. malariae, concerned, each produces distinctive symptoms and requires different treatment. They are injected into the blood of humans by the females of Anopheline mosquitoes during their act of sucking blood upon which they live. Of the hundred and forty or so different kinds of Anopheline mosquitoes, fortunately only about fifteen of these are important vectors of malaria. Thus in Africa the main carriers are Anopheles gambice and $A$. funestus; in America they are A. quadrimaculatus, $A$. punctipennis and $A$. crucians; and in India, A. stephensi, A. culicifacies and A. rossi, and so on.

Trypanosomiasis, or sleeping sickness, unlike malaria, is confined to Africa. Human sleeping sickness is caused by two species of trypanosomes, $T$. gambiense and $T$. rhodesiense. The latter produces a virulent type of the disease particularly difficult to control by drugs. The trypanosomes responsible for trypanosomiasis among domestic animals differ from those affecting humans. Of veterinary importance, mention may be made of $T$. congolense and $T$. vivax, of which the former is much the more virulent among cattle and presents the most serious veterinary problem. T. brucei is generally fatal to horses, while $T$. simice is a strain particularly dangerous to pigs. The organism responsible for transmission of the disease is the tsetse fly. Among the many species of tsetse, Glossina morsitans and $G$. pallidipes range over wide areas of bush, scrub and forest country and are found in all altitudes up to about 5,000 ft. A fly of a different habitat is $G$. palpalis, which generally lives in the proximity of water.

For Africa, especially equatorial Africa, trypanosomiasis is just as grave a problem as malaria, for where tsetse rules uncontrolled, domestic animals cannot exist, and thus vast tracts of valuable grazing land which fall within the fly-belt are left unstocked and uninhabited. As a result, the number of cattle in Africa is tragically small, but even so over-grazing occurs in many areas. In turn, the human population suffers from a deficiency of animal protein, the soil loses fertility due to lack of manure and generally conditions are created wherein disease, poverty and misery alone thrive.

* From a Friday Evening Discourse at the Royal Institution on May 14.
Malaria and trypanosomiasis constitute, without doubt, the biggest hindrance to the economic, social and political development of those territories afflicted by them. Until control of these diseases is effected, we cannot reasonably expect native communities to be sufficiently vigorous, either physically or mentally, to be entrusted with the many responsibilities which the rapid imposition of our social and political systems must throw upon them.

There are two distinct approaches to the problem. We can attempt either to destroy the parasites in man and animals, or we can concentrate our attention on the eradication of the vectors themselves. Both lines of investigation have been actively explored with considerable success for many years.

The search for synthetic drugs for combating both malaria and sleeping sickness has been pursued with increasing tempo ever since Paul Ehrlich, the brilliant founder of modern chemotherapy, established in the first years of the present century the principle that infectious diseases could be cured by employing specific chemical agents to bring about the selective destruction of the invading parasites.

\section{Chemotherapy of Human and Animal Trypano- somiasis and of Malaria}

With the experimental production of trypanosomiasis in mice and rats by Laveran and Mesnil in 1902 and the demonstration by Thomas in Liverpool in 1905 of the trypanocidal activity of atoxyl (I), Ehrlich decided to focus his attention on compounds of arsenic, rather than pursue his studies on purely organic compounds where some promising results had already been attained in mouse trypanosomiasis with a dyestuff, trypan red. As is well known, the culminating point of this series of investigations was the discovery of 'Salvarsan' (II) by Ehrlich and Hata in 1910 as a cure, not for sleeping sickness, but for the spirochætal infection syphilis. For human sleeping sickness the most successful and widely used arsenoorganic compound is still 'Tryparsamide' (III), first described by Jacobs and Heidelberger in the United States in 1919. Its virtue lies in the fact that it is the only drug with any action in the deadly late stage of sleeping sickness when trypanosomes have penetrated into the central nervous system.

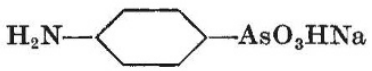

[I]

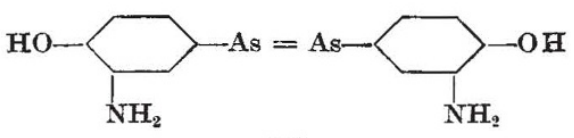

[II]

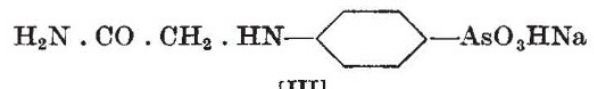

[III]

Turning now to purely organic compounds, the search for trypanocides along the lines of Ehrlich's azo dye, trypan red, has led to the discovery in Germany of Bayer 205, also known as 'Germanin', 'Suramin', 'Antrypol', etc. This substance represents the most successful chemotherapeutic agent so far discovered for human sleeping sickness in its early stages. A single dose confers a trypanocidal power on the blood for a long period, while resistance of trypanosomes to it is acquired more slowly than with 


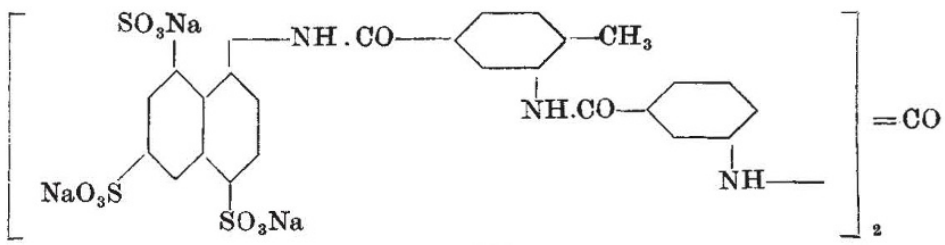

[IV]

arsenical preparations. Furthermore, it is of value against $T$. rhodesiense, where arsenicals are ineffective. On the other hand, it is of no use in the later stages of the disease, and this seems to suggest that it cannot penetrate the blood-brain barrier.

Another highly important group of chemotherapeutic agents for human sleeping sickness are the diamidines, which have been developed in Great Britain following upon an investigation of Lourie and Warrington Yorke in Liverpool. Among the members of this series, pentamidine (V) is used on a large scale by Belgian, British and French medical services. It is an extremely powerful trypanocide for treatment of the disease in the lymphatico-blood stage, but like 'Suramin' is ineffective in cases of severe nervous involvement.

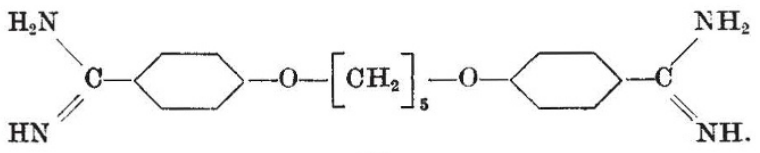

$[\mathrm{V}]$

Until recently, the search for synthetic drugs effective against the dreaded $T$. congolense infections in cattle has been unsuccessful and only tartar emetic and certain other antimonials have been found of any value. In 1931, Morgan and Walls, working in the Chemical Research Laboratory, Teddington, discovered a new series of phenanthridinium compounds, among which certain members were found to possess strong trypanocidal properties. Of these, dimidium bromide (VI) (phenanthridinium 1553) is quite outstanding and appears to cure $T$. congolense infections at extremely low dosage.

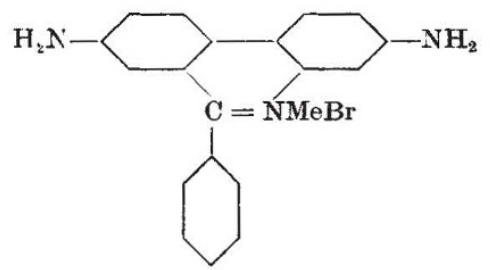

[VI]

The use of the drug is, however, not unattended by danger, as it is toxic and produces in cattle photosensitization if used in large amounts.

As a result of the world-wide distribution of malaria, the subject of specific therapy has commanded a great deal of attention. This was particularly the case during the Second World War, when both British and American troops were operating in some of the worst malarious spots in the world. The position was aggravated by the fact that quinine, the ordinary prophylactic and curative drug, became unavailable in consequence of the Japanese invasion of Java, which cut off our supplies of cinchona bark.
The possibility of studying the effect of drugs upon the malaria parasites was opened up when Roehl, one of Ehrlich's pupils, developed a method in 1926 of transmitting a related infection, Plasmodium relictum, to canaries. Following upon this discovery, chemical research work was actively pursued and rapidly resulted in the discovery in Germany of 'Plasmoquin' (VII) ('Pamaquin'), followed shortly afterwards by that of 'Atebrin' ('Mepacrine') (VIII) in 1930 This latter compound has proved to be a more<smiles>CCN(CC)CCC(C)NC1CCCC2CCCNC21</smiles>

[VII]<smiles>CCN(CC)CCCCC(C)C</smiles>

effective suppressive than quinine, and its manufacture in Britain was begun during the War. The discovery by Curd, Davey and Rose of the important antimalarial 'Paludrine' (IX) in 1944 as a result of brilliantly planned war-time research in the laboratories of Imperial Chemical Industries, Ltd., at Blackley, marks a still further striking advance in chemotherapy. As is seen from the formula, 'Paludrine' is an entirely novel drug quite unrelated structurally to either 'Pamaquin' or 'Mepacrine'. Unlike the latter, it is colourless and hence produces no discoloration of the skin. At the same time, it is less toxic, and both for prophylactic and curative purposes is vastly superior.

$$
\mathrm{Cl}-\longrightarrow \mathrm{NH} \cdot \underset{\substack{\mathrm{NH} \\[\mathrm{IX}]}}{\mathrm{C}-\mathrm{NH}} \underset{\mathrm{NH}}{\mathrm{C}-\mathrm{NH}} \cdot \mathrm{CH}\left(\mathrm{CH}_{3}\right)_{2}
$$

\section{Attacking the Insect Vector}

No one can question the great importance of the use of drugs for the treatment of either malaria or trypanosomiasis; but it is well recognized that in our Colonial territories with their many tribal com. munities, or in India with its teeming population, there is as yet no practical possibility of stamping out insect-borne diseases by such methods. The only alternative is to secure control by exterminating the vectors.

The idea of eradicating malaria and sleeping sickness in this way is, of course, not novel. The attack upon the mosquito by the drainage of swamps, the spreading of oil on water and the use of Paris Green for dusting to kill larvæ, and the spraying of houses 
with pyrethrum extract in kerosene are all methods which have been practised for a great many years. In 1930, a serious epidemic of malaria broke out in Brazil due to the introduction of Anopheles gambice into that country, probably by sea, from Africa. An area of 12,000 square miles was aflected, but through the joint co-operation of the Brazilian Government and the Rockefeller Foundation complete eradication of the species was attained. Similarly in 1942, A. gambice spread from Central Africa into Egypt, causing a serious epidemic of malaria. The Rockefeller Foundation experts were again called upon to assist the Egyptian Government. Paris Green was employed as the principal insecticide and applied to all potential breeding places. Houseto-house spraying with pyrethrum was also employed throughout the whole of the infested area. By 1945 the area was free from infestation. I mention these two campaigns as they serve to demonstrate what can be achieved by careful planning. The cost both in money and labour was high, but the extermination of the disease-carrying mosquitoes was achieved.

With the discovery of the newer and almost unbelievably potent insect-killing chemicals D.D.T. (dichlorodiphenyl-trichloroethane) (X) and benzene hexachloride ('Gammexane') the whole scheme of things has, in my opinion, become transformed. We have in these substances enormously powerful weapons for the waging of successful war against the mosquito, the tsetse and other vectors of human diseases.

So much has already been written about these two insecticides that it is unnecessary for me to do more than recall the fact that, like pyrethrum, they are contact poisons; but unlike the natural material which rapidly oxidizes in air and so loses its potency, D.D.T. is a comparatively stable substance remarkably resistant to oxidation, and thus capable of exerting insecticidal effects upon sprayed areas for prolonged periods. In addition to the above substances, many other powerful synthetic insecticides and miticides of promise have been produced in the United States. Of these, mention may be made of 'Chlordane', a chlorinated indane derivative, and 'Thiophos 3422' ('Parathion') (XI), which is said to be more effective against a wider range of insects and mites than any chemical now in practical use, and a series of alkyl polyphosphates originally prepared in Germany as a substitute for nicotine under the name 'Bladon'.

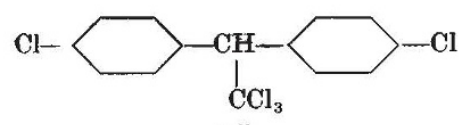

[X]

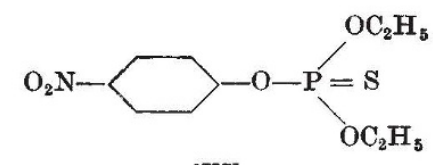

[XI]

Many experiments on insect control are being carried out in British Colonies, either by the respective Colonial administrations themselves or in conjunction with the Colonial Insecticide Committee set up by the Secretary of State for the Colonies, Mr. Creech Jones, at the beginning of 1947 .
Although D.D.T. was used so extensively and with such success during the War both by the Americans and ourselves, we were by no means satisfied that we were employing it to the best advantage. Thus we commonly used a 5 per cent solution in kerosene simply because kerosene was readily available. and we had failed in our attempts at that time to obtain good emulsions or wettable powder. Similarly, we lacked precise information as to the best methods of spraying and made do with what equipment was available. Thus in the case of aircraft sprays, use was made of equipment originally designed for gas warfare.

Even to-day, comparatively little is known of the performance in tropical countries of fixed-wing aircraft as a means of disseminating insecticides, and nothing of the efficiency of the helicopter for that purpose. Experiments on these lines are now about to be conducted in Uganda and Tanganyika using a variety of insecticide formulations, including smokes, oil solutions, emulsions, water suspensions and aerosol fogs. Much research has also to be carried out on such unsolved problems as the causes and preven. tion of absorption of insecticides by mud and thatch, the absorption and decomposition of insecticides by green leaves, the use of surface-active agents to help the spray wet the leaves and insects, and the relationship between crystal size and toxicity. These and many other questions that have arisen during field trials necessitate studies of a fundamental nature which can only be satisfactorily undertaken by a team of scientific workers, including chemists, physicists, biologists, chemical engineers and other specialists. The Colonial Insecticide Committee, with the co-operation of the Ministry of Supply, is therefore establishing a research unit at Porton to undertake the necessary investigations.

In the meantime, large-scale experiments are in hand. The first of these was initiated in 1945 in British Guiana, where more than 70 per cent of the population, some 250,000 people, live under conditions of severe endemic malaria. The initial work was directed by Mr. C. B. Symes, now officer in charge of research for the Colonial Insecticide Committee, and was later taken over and expanded by the Government malariologist. Before spraying was commenced, 700-800 mosquitoes would be found in one small bedroom. These in. cluded not only the malaria carrier, Anopheles darlingi, but also Culex fatigans, which are carriers of filariasis, and Aedes agypti, which are potential carriers of yellow fever. Spraying was carried out with 5 per cent D.D.T. at a dosage of $100 \mathrm{mgm}$. per sq. ft. to the inner surfaces of dwellings. After as long as ten months and using only a single spraying, A. darlingi mosquito captures were down to less than 2 per cent of the numbers in untreated huts. To date, approximately 84 per cent of the population are enjoying total protection from malaria. In one village where more than 60 per cent of school children showed chronic infection by malaria in 1945, only 18 per cent were infected in 1946. In 1938 the spleen index in school children was $51 \cdot 2$, whereas in 1947 it had fallen to $3 \cdot 7$.

Another highly successful experiment is being carried out in Cyprus. In the past, various efforts have been made to control the disease by treatment of water areas with oil and with Paris Green, but without success. In 1946 a large trial was conducted in the Karpass Peninsula ovar a total area of some 
7,000 square miles. The attack, directed by Mr. M. Aziz, the chief health inspector, was concentrated upon larvæ in water courses, pools, wells, etc. Spraying was carried out in most places every fourteen days from April to the end of October, when Anopheles, both adult and larvæ, were completely eliminated from the area. The work was being extended in 1947 and it was confidently anticipated that the complete eradication of mosquitoes from Cyprus could be expected within two or three years.

A malaria eradication experiment is now being prepared to be conducted in the island of Mauritius, commencing in the autumn. Malaria was introduced into the island about 1862 and is now endemic. The disease is the principal cause of death in the Colony, the population of which is about 420,000. Most of the infection is due to $A$. funestus, supplemented by A. gambice. Apart from the highest part of the island, which excludes some five thousand houses from a total of eighty-three thousand dwellings, all houses and cattle and goat sheds in the remainder of the island are to be treated by the application of residual insecticidal formulations three times a year over a period of two years. If necessary, the extension of spraying to breeding grounds will be put in hand.

Large trials are also in progress in East Africa. These are being conducted by the Colonial Insecticides Research Unit in Uganda, and cover both work on mosquitoes and tsetse flies. An interesting field experiment was carried out in a rural area north of Entebbe in Uganda, in which some two thousand houses of the mud wall and thatched roof type were divided into six areas and treated with six different formulations of D.D.T. and benzene hexachloride. All treatments caused striking reductions in popula. tions of mosquitoes in houses. Four sprayings prevented the usual seasonal increase of malaria, and two of these apparently resulted in a reduction of malaria by about 50 per cent. These results were obtained over two wet seasons.

An important factor in field trials is the reaction of the people to the experiments, especially as they involve removal of foodstuffs, clothes, etc., from the rooms to be sprayed. Actually Mr. Symes relates that the recəption everywhere was so good that at times it became embarrassing. For the first time in their lives these people experienced an undisturbed night's sleep, free from the evil presence of hundreds of biting mosquitoes as well as bed bugs, 'chigger' fleas which burrow under the skin and nails of feet and hands and cause septic sores and many other pests.

\section{Tsetse Flies}

Interesting and promising results have also been obtained in field experiments with insecticides conducted by the Uganda research team on the tsetseinfested islands and shores of Lake Victoria (in Central Africa), by the South Africans in South Africa, and by the East African Tsetse Research Department in Tanganyika. Tsetse fiies, both males and females, live by sucking the blood of animals, including domestic animals and man, where these are available, and they breed and live in bush (or jungle) of various kinds. Their young spend all their development period-some eight weeks upwards-in the soil, so that they are difficult to get at. It is the adult $\mathrm{fy}$, therefore, while it is resting on leaves, tree-trunks and stones in the bush, or actually in flight looking for food, or while feeding on an animal, that is vulnerable to attack with insecticides.

Two obvious methods are the spraying of the bush and the spraying of cattle with contact insecticides. The first method has been tried on a number of small islands of 100 acres or so and on stretches of dense shore bush on Lake Victoria. Solutions and emulsions of D.D.T. and benzene hexachloride were applied with small knapsack sprayers to bush in places where the flies concentrated or patrolled. In order to do this and to do the necessary preliminary survey of fly densities, paths were cut through the bush. It was, of course, possible to spray only a small proportion of the total bush in this manner. In spite of this, the reduction in the fly population in the last few experiments was about 98 per cent. In one trial no flies could be found for nearly three months after the last of four sprayings. While this work was going on, it was discovered that the oil solutions that were being used appeared to lose their effect on flies after about a week because a very large proportion, sometimes as much as 80 per cent, was absorbed by the leaves and stems of the trees and bush. One of the urgent inquiries, therefore, is now to find formulations of D.D.T. and benzene hexachloride that will not be absorbed by plants and trees, and it seems that certain types of emulsions or wettable powders may suit in this way.

Since such a large proportion of the total flies were killed by treatment of so small a proportion of the bush, it is thought that by increasing the area sprayed, even the last 2 per cent of flies will have difficulty in escaping. It is proposed, therefore, to do this, and since no known type of ordinary spraying equipment is suitable for use in these large areas of dense bush, the spray is to be applied from aircraft. Extensive trials of this method are now planned to begin in a few months.

Trials of insecticidal smokes and fogs drifted through the bush have also been conducted with very promising results. The smokes have been produced from grenades and canisters, filled with burning mixtures and the insecticides mixed together. The fog was discharged from a special machine.

The South Africans have gone further than this with trials of insecticidal smokes for the control of tsetse flies (G. pallidipes). For the past two years or so they have used aircraft for this work and have treated about 170 square miles several times with smoke made from a 20 per cent solution of D.D.T. in toluene and fuel oil. The aircraft fly just above the tree-tops and the smoke is produced from their exhaust pipes, which are connected to the internal spray-tanks for this purpose. Kills of tsetse have been good over the areas as a whole (up to more th in 99 per cent), but small numbers of flies have been left unharmed in dense evergreen thickets to which the smoke has not penetrated. These small pockets are now being dealt with by means of smoke canisters. South Africa has expended more than $£ 300,000$ and much effort on this work, and has had the full co-operation of its Air Force. The British effort has been much less costly so far, but it is likely to build up to a similar order of magnitude in the near future -in fact it must, if we are to deal with this problem in anything like an adequate fashion.

There is a second method of application, namely, the spraying of cattle with insecticide so that flies settling on them to feed come into contact with the insecticide crystals and so are affected. This has been 
tried by the Tsetse Research Department of Tanganyika. After preliminary work, they sprayed 350 cattle once a week for thirteen weeks and then twice a week for another eight weeks with 9 per cent D.D.T. solution in monkeynut oil plus resin. The cattle after each spraying were herded in small groups of five or six over an area of about five square miles of bush infested with the tsetse ( $G$. pallidipes). At the end of this period the tsetse had been reduced by about 80 per cent. During this work it was found that the solution when applied to cattle lost its toxicity in a few days, though the same solution applied to a dried ox skin was toxic for months. Subsequent investigation has shown that this is due essentially to absorption of the solution into and through the living skin. This line of investigation will continue.

Effective application of insecticides is not quite the simple problem that it may seem. Chemical, biological, physical and engineering studies are all deeply involved and intermixed. It is only in so far as we are able to cope with these interrelated problems that we may expect to make progress. Our effort so far, however prolnising-and the results are very heartening - is a very meagre one. We in the British Commonwealth of Nations are faced with all the major insect-borne diseases and pests of animals and crops in larger measure than any other group of peoples. In the past there has seemed to be no way of dealing with these problems in any reasonable period. But with the new insecticides, supplementing the best of the old, we have weapons of which we have not hitherto dreamed. The future holds a challenge which we dare not refuse.

\section{THE HEALTH OF THE SCHOOL CHILD}

\section{By DR. ROBERT SUTHERLAND}

Medical Adviser and Secretary, Central Council for Health Education

$\mathrm{N}^{\circ}$ OT the least of British war-time triumphs was the way the health of the children was maintained and even improved. Except in 1940-41 the death-rates in the war years were equal to or less than pre-war rates. There was an improvement in the height and weight of both sexes, the number of children with really bad nutrition was roughly halved, and the amount of anæmia was reduced.

These striking improvements took place although many children suffered the stresses of air raids and the disruption of evacuation, and although the staffs of school medical and school dental services were reduced because many of their members were serving in the armed forces.

There is no doubt, therefore, that these encouraging results were largely due to a raising of the standard of living of the poorer half of the population, to our very well-designed system of rationing, with its priorities for mothers and children, and to the tenfold increase in school dinners and the 30 per cent increase in the taking of school milk.

Part of the fall in the death-rates was due to a reduction in deaths from respiratory infections, notably pneumonia, and from diphtheria. The development of ehemotherapy probably had much to do with the fall in pneumonia deaths, and the diphtheria immunization campaign introduced in 1942 was certainly largely responsible for the striking reduction in the diphtheria deaths.

The report of the Chief Medical Officer of the Ministry of Education for the years 1939-45* very properly stresses the ground that has been gained in difficult circumstances. But equally properly Sir Wilson Jameson notes some challenging facts that still confront us.

The nutrition of one out of every six (or at best one out of every nine) of our school children still leaves something, and in many cases much, to be desired. Despite the fact that the pre-school child is in many ways the most cared-for citizen, only one in five of our five-year-olds has had no dental decay: the average child aged five has four teeth missing, filled or decayed.

In some places one in ten of the children in our schools are educationally sub-normal, and-evidence of poor environment or poor parental care-one in ten children have head lice or nits.

Nutrition, of course, is a very complex matter which depends on much more than diet. Insufficient sleep, infectious diseases of childhood, lack of exercise, unhappiness, insecurity, all prevent a child from getting full advantage from his diet. Since less than half the mothers in Britain, however, get for their children the vitamin extras to which they are entitled, it is probable that the diet is not always as good as it might be. Nine-tenths of school children are now getting school meals, and there is little doubt that as a consequence we shall, over a period of years, see a considerable improvement in their nutrition; but, of course, no official provision is at present made, except in nursery schools, for well-balanced meals for the pre-school child. Although the school child gets one-third of a pint of milk a day entirely free of charge, milk for the pre-school child (except in cases of great need) has to be paid for, although at a cheaper rate.

It is certainly an indictment of our separation allowances for the dependants of Service men that the children of Service men showed a lower amount of hæmoglobin at all ages less than ten years.

Many of the 10 per cent of children who are educationally sub-normal are merely backward as a result of poor health or poor nutrition, so that here there is a close relation between the child's intellectual and physical health. Indeed, since in some cases a child may fail to use his intelligence principally because of emotional disturbances, emotional health is involved as well. The importance of emotional health is indeed recognized in the report, and developments of the Child Guidance Service are forecast. There are, too, throughout the report many indications of a clearer recognition of the child's unity of mind and body and of the consequent need for the closest possible co-operation between the teacher, doctor and nurse; and considerable space is given to a consideration of how physical education and health education can help.

The importance of the home and of factors outside the home is rightly stressed. However much school meals are developed, and other existing responsibilities of the parent taken over by the teacher or the school doctor or nurse, the health of the school child will still be largely determined by the care given

* The Health of the School Child. Report of the Chtef Medical Officer of the Ministry of Education for the Years 1939-1945. Pp. 148. (London: H.M. Stationery Offlce, 1947.) 28. 6d. net. 